\title{
Translation Studies Orientations: A Case Study on Asian and European Journals
}

\author{
Nadieh Rafiee ${ }^{1}$, Azadeh Nemati ${ }^{2, *}$ \\ ${ }^{1}$ Department of Translation Studies, Science and Research, Branch, Islamic Azad University, Fars, Iran \\ ${ }^{2}$ Department of English Language Teaching, Jahrom Branch, Islamic Azad University, Jahrom, Iran \\ *Corresponding Author: azadehnematiar@yahoo.com
}

Copyright (C) 2014 Horizon Research Publishing All rights reserved.

\begin{abstract}
The present study aimed at determining whether there existed any significant differences among different Translation Studies (TS) research areas in Asian as well as European journals. This study focused on the twelve main areas of TS listed by Williams and Chesterman (2002). To do so, six TS journal (three Asian and three European ones) were selected based on simple random sampling. Then, out of each journal, twenty articles were selected through simple random sampling. Having determined the corresponding TS research areas, each paper was placed in one of the twelve listed research areas. The results of the frequency analyses showed statistically significant differences among the frequencies of TS research areas in Asian and European journals $(p<0.05)$. While the most frequent research areas in Asian journals were 'Translator Training', 'Interpreting', and 'The Translation Process', the most frequent research areas in European journals were observed to be 'Genre Translation', 'Text Analysis and Translation', 'Translation History', and 'The Translation Process' The results also revealed that 'Multimedia Translation' and 'Terminology and Glossaries' were among the least frequent research areas, both in Asian and European journals.
\end{abstract}

Keywords Translation Studies, Asian TS Journals, European TS Journals, The Map, TS Research Areas

\section{Introduction}

Translation Studies (TS) is defined as the field of study devoted to describing, analyzing and theorizing the processes, contexts and products of the act of translation as well as the (roles of the) agents involved (Williams \& Chesterman, 2002). Throughout the history, TS has been regarded as an inter-disciplinary field of science. This was a common view about TS, especially during 1980s (Snell-Hornby, 1995). As Munday (2008) believes, it has been less than a century since the emergence of TS as an academic discipline.
On the other hand, research is defined broadly as a "systematic investigation towards increasing the sum of knowledge" (Chambers, 1989, p. 845). One would also agree with Gillham $(2000$, p. 2) that "research is about creating new knowledge, whatever the disciplines". Innovation is vital if a discipline is to grow and prosper. However, the definition of 'new knowledge' varies according to the level at which the research is undertaken. An essay at advanced B.A level will clearly differ in scope from a doctoral dissertation. Creating new knowledge can consist in summarizing new research in an emerging field or providing a very small amount of new evidence to support or disconfirm an existing hypothesis at one end of the scale, to developing a new methodology for translation history at the other. The aim of TS research is therefore to make a contribution to the field which increases the sum of our knowledge. According to Williams and Chesterman (2002), one can make his/her contribution in a number of ways. These are:

- By providing new data;

- By suggesting an answer to a specific question;

- By testing or refining an existing hypothesis, theory or methodology; and,

- By proposing a new idea, hypothesis, theory or methodology.

\subsection{Statement of the Problem}

Concerning TS, there are many issues to be investigated. One would be in favor of comparative research programs, when mostly a Source Text (ST) is compared to a Target Text (TT) within a defined context (e.g., Vinay \& Darbelnet 1958, Catford 1965, etc.). Others might be oriented towards conducting correlational researches to figure out the relationship between two or more variables, the impact they have on each other, their levels of significance, and so on and so forth. All these studies are done with the aim of delving into a specific problem in the science of translation and their conductions seem crucial to the existence of this new field of science. In this regard, many studies are being carried out in different countries of the world. However, these studies might possibly differ in terms of their nature, methods, 
objectives, etc. According to Toury (1995), there might be many factors influencing these choices. Thus the present study will aim at investigating the orientations of different countries towards the science of translation through reviewing their TS journals. In fact, to figure out where the countries under investigation would stand in terms of their views about TS is the main purpose of this study.

As for some Asian countries, the pace of knowledge distribution seems to have been slower, compared with European and American countries. Machine Translation (MT), interpretation, translation as a profession, ethics in translation, etc., are some of the examples of modern TS growing in the advanced countries each and every day (Williams \& Chesterman, 2002). These issues seem to have been neglected in Asian countries like Iran. In line with the brief introduction presented on the trends of TS, there remains a debating issue: To what extent do different countries of the world differ in terms of their orientations, achievements, etc., in TS? In other words, what are the basic differences between Asian countries on the one hand, and European countries on the other? In this study, TS research areas in different countries will be investigated. To this end, a detailed framework will be used, namely Williams and Chesterman's (2002) areas of TS, discussed on the methodology section. In addition, only the journals related to TS will be chosen as the corpus of the study.

\subsection{Significance of the Study}

The present study will aim at investigating the tendencies of TS within different countries of the world. This will be carried out with special reference to two continents (i.e., Asia and Europe). This topic enjoys a new methodology. In this regard, a number of issues are listed as follows:

- Firstly, the scope of this research is related to two continents which, in turn, will present the readers with a more extended list of results and findings. Broadening the aims and scopes of a research program could possibly 'present more generalized data' (Cohen, Manion \& Morrison, 2007, p.113).

- Secondly, the orientations of Iranian researchers could be compared with those of other countries including Asian on the one hand, and European on the other. This could help Iranian researchers, professors, students, etc., in their decision makings while trying to select a topic in TS.

- Thirdly, the most and the least worked areas in TS will be investigated in different countries under study, which will be done through a recent model presented by Williams and Chesterman (2002).

There are other issues making this study significant: few studies with similar frameworks and methodologies have been carried out inside Iran. In other words, no systematic comparison has been made among Iran and abroad. Hence, the present study is assumed to contribute well to TS researchers.

\subsection{Objectives of the Study}

The followings are the most addressed objectives of the present study:

1. Investigating the TS orientations in Asian countries on the one hand, and European countries on the other;

2. Making comparisons among different countries of the world in terms of their tendencies in TS;

3. Introducing the most and the least-frequent areas of research in TS within the countries under investigation;

4. Making a review on different Asian and European journals of TS.

Accordingly, the people who might benefit from the outcome of the present research are introduced as follows:

- The authorities of TS journals, who are willing to assess the qualities of submitted articles,

- TS students who are willing to select a topic for their M.A and Ph.D. dissertations,

- TS professors, who are helping such students out through guiding them in terms of their topic selections.

\subsubsection{Research Questions}

1) Are there any significant differences among the frequencies of Williams and Chesterman's (2002) TS research areas, comparing Asian and European journals?

2) Based on Williams and Chesterman's (2002) classification, what research areas hold the highest frequencies among the others in European TS Journals?

3) Based on Williams and Chesterman's (2002) classification, what research areas hold the highest frequencies among the others in Asian TS Journals?

4) Based on Williams and Chesterman's (2002) classification, what research areas hold the lowest frequencies among the others in European TS Journals?

5) Based on Williams and Chesterman's (2002) classification, what research areas hold the lowest frequencies among the others in Asian TS Journals?

\subsubsection{Research Hypotheses}

H1. There are significant differences among the frequencies of Williams and Chesterman's (2002) TS research areas, comparing Asian and European journals.

H2. Based on Williams and Chesterman's (2002) classification, 'translation and technology', 'multimedia translation', and 'translation ethics' hold the highest frequencies among the others in European TS Journals.

H3. Based on Williams and Chesterman's (2002) classification, 'text analysis and translation' and 'the translation process' hold the highest frequencies among the others in Asian TS Journals. 
H4. Based on Williams and Chesterman's (2002) classification, 'text analysis and translation' and 'genre translation' hold the lowest frequencies among the others in European TS Journals.

H5. Based on Williams and Chesterman's (2002) classification, 'translation ethics', 'translation and technology', and 'the translation profession' hold the lowest frequencies among the others in Asian TS Journals.

\section{Review of Literature}

As mentioned before, throughout the history of translation, many models and frameworks have been introduced. Each of these models would tend to review a specific problem in TS. The first and the most systematic approach to TS was a classification made by Holmes (1988). Although the original work by this scholar was presented in 1972 in a conference in Copenhagen, it was not widely publicized until 1988. Holmes (1988) divided TS to 'pure' and 'applied' branches. The pure branch was subdivided into 'theoretical' TS on the one hand, and 'descriptive' TS on the other. While the former would deal with different theories generated in TS and thus would try to explain how TS should be, the latter would try to describe the phenomenon of translation and its related issues through explaining how TS was (cited by Munday, 2008). These main branches had in turn some sub-categories. The theoretical branch was, for instance divided into 'general' and 'partial' theories of translation, while the descriptive one was divided into 'product-oriented', 'process-oriented' and 'function-oriented' TS.

Holmes' (1988) work on TS roughly considered the applied branches of TS. In this regard, Toury (1995) tried to offer a complete overview on the sub-branches of applied TS neglected by Holmes (ibid.). To this end, Toury (ibid.) divided applied TS to three main branches including 'translation aids', 'translation criticism', and 'translator training'. Each of these branches was then sub-divided into some other narrowing categories.

Hatim (2001) was another scholar to challenge the areas of research in TS by offering a complete overview of TS research topics and methods. However, he did not show the inter-disciplinary nature of TS compared to the areas of research and research methods listed in The Map (Williams \& Chesterman, 2002).

Recent global publications on research methods and trends in TS are Unity in diversity edited by Bowker et al. (1998) on the one hand, and The Map by Williams and Chesterman (2002) on the other. While the former publication challenges the claim of inter-disciplinary characteristics as the essence of TS in view of its theoretical diversity and also disputes the existence of a general theory of translation, the latter one focuses on description of research and research methods in TS (As cited in Lan, , Dong and Chiu, 2009). In fact, the latter one listed twelve key areas of translation and suggested possible research directions for each area, roughly corresponding to Holmes' map of TS. This classification was used as the main framework of the present study.

There have been a number of empirical works carried out by different researchers around the world. For example, Liao (2007) reviewed eighteen interpretation-related theses between the years 1991 and 2004 in addition to forty-six papers related to the same area published in "Studies of Translation and Interpretations", volumes 1-10. The researcher then outlined the development of interpretation research, research method and research target language. As the result of his work, Liao (ibid.) pointed out the shortcomings in interpretation research areas in Taiwan and cited suggestions from Kurz (2001) for improvements to be made.

Yuan and Tang (2007) conducted a frequency analysis of the titles of 1610 articles in three different journals including 'Shanghai Journal of Translation', 'Chinese Translation Journal' and 'Chinese Science and Technology Translation Journal'. The results of their analyses revealed that in order of popularity, translation trends in china focused on the issues of 'translation', 'English', 'research', 'English translation', 'culture', 'theory', 'translation studies', 'interpretation', and 'technology' between the years of 2001 and 2006. The paper also pointed out the trends in certain areas.

In another study carried out by Lan et al. (2009), the research results in journals and theses published between the years 2002 and 2008 from Taiwan and abroad were compared with the aim of extracting the similarities and differences of the focuses and the methods of research between Taiwan and abroad. The results of the work in question revealed that the research methods employed in these areas were similar and that translation theories were used to analyze and solve the phenomena and problems in translation. Also, a great number of theses in translation were meant to be 'translation with commentary'. While the authors of foreign publications would have more spirit and confidence to challenge existing theories and they were more willing to use the results of other scientific research to describe and explain translation phenomena and even to solve the problems. The results also suggested that the 'multimedia translation', 'translation and technology', 'translation history', 'translation ethics' and 'translation profession' were the areas to be worked in future based on the classifications made in The Map (Williams \& Chesterman, 2002).

\section{Methodology}

\subsection{Materials}

Three Asian TS journals along with three European ones were selected to be studied. These journals were chosen in a way to represent the continent they were being published in. In addition, in order to have a control over the probable effect 
of time, the researchers chose the articles published between 2003 and 2013. Therefore, a period of ten years was studied in this work, concerning both Asian and European journals. Another important issue left to be mentioned is about the frequency of TS journals. Unlike other language-related fields of study such as Linguistics, Teaching English as a Foreign/Second Language, etc., the number of TS journals are very limited. This fact is more supportive for Asian TS journals, as compared with European ones. Table 1. describes these journals:

\subsection{The Model Used}

Within the present work, Williams and Chesterman's (2002) research areas in TS were selected as the main framework. These included twelve main areas in TS research listed as follows (Williams \& Chesterman, 2002, pp. 6-27):

1) Text Analysis and Translation

2) Translation Quality Assessment

3) Genre Translation

4) Multimedia Translation

5) Translation and Technology

6) Translation History

7) Translation Ethics

8) Terminology and Glossaries

9) Interpreting

10) The Translation Process

11) Translator Training

12) The Translation Profession

According to Lan et al. (2009), this classification roughly corresponds to Holmes' (1988) map of TS, as the research areas presented here widely differ from those proposed by
Holmes (1988). As Lan et al. (2009) claim, even the parts developed by Toury (1995) do not completely correspond to the research areas proposed by Williams and Chesterman (2002).

\subsection{Data Collection Procedure}

Twenty articles out of each journal were selected through random sampling. Generally, in each issue, there were about fifteen to twenty papers. However, it was different from journal to journal. In justifying the data collection procedure, these articles were chosen among the ones published between the years 2003 and 2013. In other words, a ten-year period of research in the so-called countries was investigated. Having gathered the data, each paper was given its own branch of TS research based on Williams and Chesterman's (2002) classification. Finally, the adhering branches of the articles published in Asian journals were summed up together in order to make a representative sample for this continent. The same procedure was carried out for the European articles.

\subsection{Data Analysis Procedure}

Having found the frequencies of each of the twelve main branches in TS research based on Williams and Chesterman's (2002) model, the differences among the frequencies of the so-called branches will be statistically tested. This was carried out through conducting several Chi-square tests, using SPSS software. The results and findings were then presented and further discussed. Each research question was separately addressed, too.

Table 1. The Asian and European Journals Selected to be Studied

\begin{tabular}{|c|c|c|c|c|}
\hline Number & $\begin{array}{c}\text { Continent } \\
\text { represented }\end{array}$ & Name of the Journal & $\begin{array}{c}\text { Country of } \\
\text { Publication }\end{array}$ & $\begin{array}{c}\text { N of Sample } \\
\text { Articles }\end{array}$ \\
\hline $\mathbf{1}$ & Asia & Translation Studies & Iran & 20 \\
\hline $\mathbf{2}$ & Asia & Chinese Translators Journal & China & 20 \\
\hline $\mathbf{3}$ & Asia & Compilation and Translation Review & Taiwan & 20 \\
\hline Total & & & UK & 20 \\
\hline $\mathbf{4}$ & Europe & The Translator & The Netherlands & 20 \\
\hline $\mathbf{5}$ & Europe & Target & Hungary & 20 \\
\hline $\mathbf{6}$ & Europe & Across Languages and Cultures & & 60 \\
\hline Total & & & & \\
\hline
\end{tabular}


Table 2. Frequency of Each Research Area in TS Based on Williams and Chesterman (2002) Categorization

\begin{tabular}{|c|c|c|c|}
\hline $\begin{array}{c}\text { Code of the } \\
\text { Research Area }\end{array}$ & Research Area & $\begin{array}{c}\text { Frequency in Asian } \\
\text { Journals }\end{array}$ & $\begin{array}{c}\text { Frequency in European } \\
\text { Journals }\end{array}$ \\
\hline 1 & Text Analysis and Translation & 3 & 8 \\
\hline 2 & Translation Quality Assessment & 4 & 12 \\
\hline 3 & Genre Translation & 1 & 3 \\
\hline 4 & Multimedia Translation & 5 & 8 \\
\hline 5 & Translation and Technology & 6 & 6 \\
\hline 6 & Translation History & 3 & 0 \\
\hline 7 & Translation Ethics & 1 & 6 \\
\hline 8 & Terminology and Glossaries & 10 & 8 \\
\hline 9 & Interpreting & 9 & 4 \\
\hline 10 & The Translation Process & 16 & 3 \\
\hline 11 & Translator Training & 0 & 3 \\
\hline 12 & The Translation Profession & & \\
\hline
\end{tabular}

\section{Results and Findings}

This study aimed to target three Asian, as well as three European TS journals. These included Translation Studies, Chinese Journal of Translators and Compilation and Translation Review as the Asian ones. Likewise, Target, The translator and Across Languages and Cultures were selected as the European samples. Having selected the journals, the data were collected. Appendix 1 shows the title of each article studied, along with its corresponding research area in TS. The frequency of each research area in TS based on Williams and Chesterman's (2002) model is presented in Table 2

In order to understand the differences better, the researchers presented the results related to the collected data in a bar-graph, too. This is available in Figure 1., as follows:

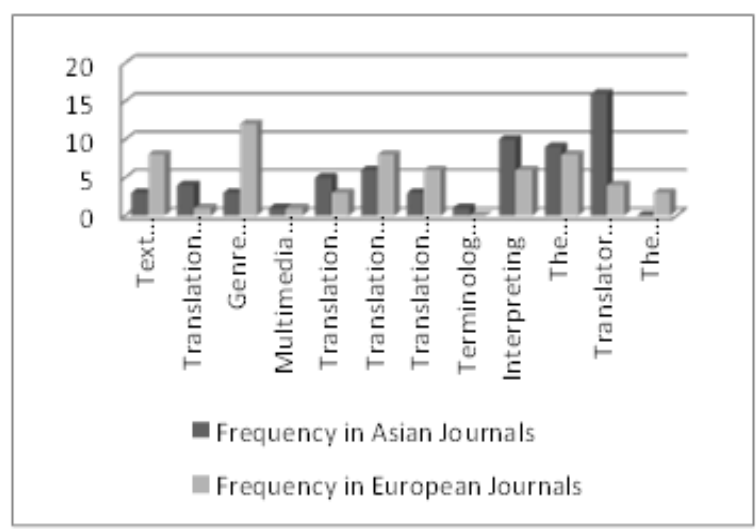

Figure 1. A Comparison Among the Frequency of Each Research Area in Asia and Europe

To see whether the differences among the research areas in each continent held any statistically significant differences, the researchers used the Chi-square procedure. In this regard, the test was carried out among pairs of each research area frequencies in different journals. It is important to mention that the areas with the frequencies of 0 were automatically omitted by the SPSS software. This means that the differences among these pairs have been observed to be statistically significant. These research areas included 'Terminology and Glossaries' on the one hand, and 'The Translation Profession' on the other. In addition, the areas with the similar frequencies in both Asian and European journals were not considered. For this study, there was only one research area detected to be so, i.e., 'Multimedia Translation' with the frequency of 1 in both continents. The results of the testes related to the other nine research areas are as followings:

\subsection{Text Analysis and Translation}

Concerning 'Text Analysis and Translation', the frequencies of related articles were observed to be 3 and 8 for Asian and European journals respectively. First, Table 3. provides a comparison among the frequencies of each journal type:

Table 3. A Comparison Among the Frequencies of Asian and European Journals: 'Text Analysis and Translation'

\begin{tabular}{|c|c|c|c|}
\hline & Observed N & Expected N & Residual \\
\hline Asia & 3 & 6 & -3 \\
\hline Europe & 8 & 6 & 2 \\
\hline Total & 11 & & \\
\hline
\end{tabular}

To see whether the differences were of any statistical significance or not, the Chi-Square test was conducted. Table 4. presents the results of this test: 
Table 4. Chi-square Test Results for 'Text Analysis and Translation'

\begin{tabular}{|c|c|}
\hline & $\mathrm{f}$ \\
\hline Chi-Square & 2.273 \\
\hline $\mathrm{df}$ & 1 \\
\hline Asymp. Sig. & 0.1317 \\
\hline
\end{tabular}

As the results of the Chi-Square test revealed, in 'Text Analysis and Translation' research area, there did not exist any statistically significant differences among the frequencies of Asian and European articles $(p>0.05)$.

\subsection{Translation Quality Assessment}

Table 5. contains some basic information on the frequencies of the articles in both Asian and European journals. These frequencies were observed to be 4 and 1 respectively.

Table 5. A Comparison Among the Frequencies of Asian and European Journals: 'Translation Quality Assessment'

\begin{tabular}{|c|c|c|c|}
\hline & Observed N & Expected N & Residual \\
\hline Asia & 4 & 3 & 1 \\
\hline Europe & 1 & 3 & -2 \\
\hline Total & 5 & & \\
\hline
\end{tabular}

In order to find out whether the differences were of any statistical significance or not, the Chi-Square test was conducted. Table 6. presents the results of this test:

Table 6. Chi-square Test Results for 'Translation Quality Assessment'

\begin{tabular}{|c|c|}
\hline & $\mathrm{f}$ \\
\hline Chi-Square & 1.800 \\
\hline df & 1 \\
\hline Asymp. Sig. & 0.1797 \\
\hline
\end{tabular}

As the results of the Chi-Square test showed, in 'Translation Quality Assessment' research area, there did not exist any statistically significant differences among the frequencies of Asian and European articles $(p>0.05)$.

\subsection{Genre Translation}

Table 7. A Comparison Among the Frequencies of Asian and European Journals: 'Genre Translation'

\begin{tabular}{|c|c|c|c|}
\hline & Observed N & Expected N & Residual \\
\hline Asia & 3 & 8 & -5 \\
\hline Europe & 12 & 8 & 4 \\
\hline Total & 15 & & \\
\hline
\end{tabular}

Likewise, Table 7. contains some basic information on the frequencies of articles in both Asian and European journals. These frequencies were observed to be 3 and 12 respectively.

In order to figure out whether the differences were of any statistical significance or not, the Chi-Square test was conducted. The results of this test are shown in Table 8., as follows:
Table 8. Chi-square Test Results for 'Genre Translation'

\begin{tabular}{|c|c|}
\hline & $\mathrm{f}$ \\
\hline Chi-Square & 5.400 \\
\hline $\mathrm{df}$ & 1 \\
\hline Asymp. Sig. & 0.0201 \\
\hline
\end{tabular}

According to the results of the Chi-Square test, concerning 'Genre Translation' research area, there existed statistically significant differences among the frequencies of Asian and European articles $(p<0.05)$. Therefore, it could be stated that the frequencies of the Asian and European papers in this research area were observed to be statistically significant.

\subsection{Translation and Technology}

The same procure was carried out for the 'translation and Technology' research area. Accordingly, table 9. contains the basic information related to the Chi-Square test. It is important to mention that the frequencies of this research area were 5 for Asian and 3 for European journals.

Table 9. A Comparison Among the Frequencies of Asian and European Journals: 'Translation and Technology'

\begin{tabular}{|c|c|c|c|}
\hline & Observed N & Expected N & Residual \\
\hline Asia & 5 & 4 & 1 \\
\hline Europe & 3 & 4 & -1 \\
\hline Total & 8 & & \\
\hline
\end{tabular}

The Chi-Square test was then conducted as follows:

Table 10. Chi-square Test Results for 'Translation and Technology'

\begin{tabular}{|c|c|}
\hline & $\mathrm{f}$ \\
\hline Chi-Square & 0.500 \\
\hline df & 1 \\
\hline Asymp. Sig. & 0.4795 \\
\hline
\end{tabular}

Based on the findings of the Chi-Square test showed in table 10., in 'Translation and Technology' research area, there did not exist any statistically significant differences among the frequencies of Asian and European articles $(p>0.05)$.

\subsection{Translation History}

Table 11. A Comparison Among the Frequencies of Asian and European Journals: 'Translation History'

\begin{tabular}{|c|c|c|c|}
\hline & Observed N & Expected N & Residual \\
\hline Asia & 6 & 7 & -1 \\
\hline Europe & 8 & 7 & 1 \\
\hline Total & 14 & & \\
\hline
\end{tabular}

Table 11. shows the researchers' concern in terms of the differences within 'translation History' research area. The frequencies in question were 6 for Asian, while 8 for European journals. 
Table 12. Chi-square Test Results for 'Translation History'

\begin{tabular}{|c|c|}
\hline & $\mathrm{f}$ \\
\hline Chi-Square & 0.286 \\
\hline df & 1 \\
\hline Asymp. Sig. & 0.5930 \\
\hline
\end{tabular}

With insights from the results of the Chi-Square test presented in table 12., in 'Translation History' research area, there did not exist any statistically significant differences among the frequencies of Asian and European articles $(p>0.05)$.

\subsection{Translation Ethics}

Table 13. shows the basic statistics on the Chi-Square test applied by the researchers. This test was done with special reference to 'Translation Ethics' research area:

Table 13. A Comparison Among the Frequencies of Asian and European Journals: 'Translation Ethics'

\begin{tabular}{|c|c|c|c|}
\hline & Observed N & Expected N & Residual \\
\hline Asia & 3 & 5 & -2 \\
\hline Europe & 6 & 5 & 1 \\
\hline Total & 9 & & \\
\hline
\end{tabular}

As shown in table 13., the frequencies of the papers were observed to be 3 and 6 for Asian and European journals respectively. Accordingly, the following table shows the results and findings of the Chi-Square test.

Table 14. Chi-square Test Results for 'Translation Ethics'

\begin{tabular}{|c|c|}
\hline & $\mathrm{f}$ \\
\hline Chi-Square & 1.000 \\
\hline $\mathrm{df}$ & 1 \\
\hline Asymp. Sig. & 0.3173 \\
\hline
\end{tabular}

With insights from the results of the Chi-Square test presented in table 14., in 'Translation Ethics' research area, there did not exist any statistically significant differences among the frequencies of Asian and European articles $(p>0.05)$.

\subsection{Interpreting}

Table 15. A Comparison Among the Frequencies of Asian and European Journals: 'Interpreting'

\begin{tabular}{|c|c|c|c|}
\hline & Observed $\mathrm{N}$ & Expected $\mathrm{N}$ & Residual \\
\hline Asia & 10 & 8 & 2 \\
\hline Europe & 6 & 8 & -2 \\
\hline Total & 16 & & \\
\hline
\end{tabular}

Table 15. presents the basic information on the Chi-Square test applied by the researchers. This test was done with special reference to 'Interpreting' research area:
As illustrated in table 15., the frequencies of the papers were observed to be 10 and 6 for Asian and European journals respectively. Accordingly, the following table shows the results and findings of the Chi-Square test.

Table 16. Chi-square Test Results for 'Interpreting'

\begin{tabular}{|c|c|}
\hline & $\mathrm{f}$ \\
\hline Chi-Square & 1.000 \\
\hline Df & 1 \\
\hline Asymp. Sig. & 0.3173 \\
\hline
\end{tabular}

With insights from the results of the Chi-Square test presented in table 16., in 'Interpreting' research area, there did not exist any statistically significant differences among the frequencies of Asian and European articles $(p>0.05)$.

\subsection{The Translation Process}

The basic information on the Chi-Square test applied by the researchers concerning 'The Translation Process' research area is shown in the following table:

Table 17. A Comparison Among the Frequencies of Asian and European Journals: 'The translation process'

\begin{tabular}{|c|c|c|c|}
\hline & Observed N & Expected N & Residual \\
\hline Asia & 9 & 9 & 0 \\
\hline Europe & 8 & 9 & -1 \\
\hline Total & 17 & & \\
\hline
\end{tabular}

As demonstrated in table 17., the frequencies of the papers were observed to be 9 and 8 for Asian and European journals respectively. Accordingly, the following table shows the results and findings of the Chi-Square test.

Table 18. Chi-square Test Results for 'The Translation Process'

\begin{tabular}{|c|c|}
\hline & $\mathrm{f}$ \\
\hline Chi-Square & 0.059 \\
\hline Df & 1 \\
\hline Asymp. Sig. & 0.8084 \\
\hline
\end{tabular}

With insights from the results of the Chi-Square test presented in table 18., in 'The Translation Process' research area, there did not exist any statistically significant differences among the frequencies of Asian and European articles $(p>0.05)$.

\subsection{Translator Training}

Finally, the researchers tended to investigate the differences among the frequencies of Asian and European journals with insights form 'Translator training' research area. The frequencies related to these articles were 16 and 4 respectively. Some basic information are shown in the following table: 
Table 19. A Comparison Among the Frequencies of Asian and European Journals: 'Translator Training'

\begin{tabular}{|c|c|c|c|}
\hline & Observed $\mathrm{N}$ & Expected $\mathrm{N}$ & Residual \\
\hline Asia & 16 & 10 & 6 \\
\hline Europe & 4 & 10 & -6 \\
\hline Total & 20 & & \\
\hline
\end{tabular}

In order to figure out whether the differences were of any statistical significance or not, the Chi-Square test was conducted. The results of this test are shown in Table 20., as follows:

Table 20. Chi-square Test Results for 'Translator Training'

\begin{tabular}{|c|c|}
\hline & $\mathrm{f}$ \\
\hline Chi-Square & 7.200 \\
\hline Df & 1 \\
\hline Asymp. Sig. & 0.0073 \\
\hline
\end{tabular}

According to the results of the Chi-Square test, concerning 'Translator Training' research area, there existed statistically significant differences among the frequencies of Asian and European articles $(p<0.05)$. Therefore, it could be stated that the frequencies of the Asian and European papers in this research area were observed to be statistically significant.

\section{Discussion}

\section{1. Discussion on the First Research Question}

As the results of the study revealed, generally, there were statistically significant differences among the frequencies of Williams and Chesterman's (2002) TS research areas, comparing Asian and European journals. Among the twelve research areas presented by Williams and Chesterman (2002), four of them were observed to hold statistically significant differences $(p<0.05)$. These areas included 'Genre Translation', 'Terminologies and glossaries', 'Translator training', and 'The Translation profession'.

\section{2. Discussion on the Second Research Question}

As the findings of the study revealed, 'Genre translation' was the most frequent research area in European TS journals. This held the frequency of 12. Likewise, 'Text Analysis and Translation', 'Translation History', and 'The Translation Process' shared the fact of being the second most frequent research areas $(\mathrm{f}=8)$.

The findings of the work supported Yuan and Tang's (2007) study who carried out a frequency analysis of the titles of 1610 articles in three different journals including "Shanghai Journal of Translation”, "Chinese Translation Journal" and "Chinese Science and Technology Translation Journal". The results of their data analyses showed that in order of popularity, translation trends in china focused on the issues of 'translation', 'English', 'research', 'English translation', 'culture', 'theory', 'translation studies', 'interpretation', and 'technology' between the years of 2001 and 2006. The paper also pointed out the trends in certain areas.

\subsection{Discussion on the Third Research Question}

Based on the findings of the study, 'Translator Training', 'Interpreting', and 'the Translation Process' were the most frequent research areas in Asian journals. These areas were observed to have the frequencies of 16, 10, and 9 respectively.

The framework used in this section supported Lan et al.'s work (2009). They compared research results in journals and theses published between the years 2002 and 2008 from Taiwan and abroad with the aim of extracting the similarities and differences of the foci and the methods of research between Taiwan and abroad. The results of this work revealed that the research methods employed in these areas are similar and that translation theories were used to analyze and solve the phenomena and problems in translation.

Also, a great number of theses in translation detected in Lan et al.'s (2009) study were 'translation with commentary'. While the authors of foreign publications have more spirit and confidence to challenge existing theories and they are more willing to use the results of other scientific research to describe and explain translation phenomena and even to solve the problems. The results also suggested that 'multimedia translation', 'translation and technology', 'translation history', 'translation ethics' and 'translation profession' are the areas to be worked in future based on the classifications made in The Map (Williams \& Chesterman, 2002).

\subsection{Discussion on the Fourth Research Question}

The second and the third research questions tended to deal with the most frequent TS research areas based on Williams and Chesterman's (2002) classification. In contrast, the fourth and the fifth research question aim to deal with the least frequent research areas of TS based on the model in question. In other words, the most neglected research areas were targeted in these two research questions. As the findings of the study showed, 'Terminology and Glossaries' held the frequency of 0 as compared with the other eleven research areas. Thus, it could be stated that this research area seems to have been neglected by European scholars and researchers. The second least frequent areas were 'Translation Quality Assessment' and 'Multimedia Translation', both with the common frequencies of 1 .

\subsection{Discussion on the Fifth Research Question}

According to the findings of the study, the 'Translation Profession' was the least frequent research area in Asian journals $(f=0)$. In addition, 'Multimedia Translation' and 'Terminology and Glossaries' shared the common frequency of 1 . 
Based on the observed data, 'Multimedia Translation' and 'Terminology and Glossaries' were among the least frequent research areas detected both in Asian and European journals. This might be possibly due to the reason that these types of research in TS have lost their popularity during the short developing history of TS. In other words, several different studies on the issues of multimedia translation along with the notion of terminologies and glossaries have been conducted to date. For example, the concept of equivalence was a core topic of discussion during the 1960s and 1970s (Newmark, 1988). Nowadays, other topics are being investigated. Therefore, it would not be surprising to see that these two research areas are being neglected, both in Asian and European journals.

All in all, the framework of the present study was in accordance with the one carried out by Liao (2007). In that study, the researcher reviewed eighteen interpretation-related theses between the years 1991 and 2004 in addition to forty-six papers related to the same area published in "Studies of Translation and Interpretations", volumes 1-10. Liao (2007) outlined the development of interpretation research, research method and research target language. As the result of his work, Liao (2007) mentioned some shortcomings in interpretation research area in Taiwan and quoted some suggestions from Kurz (2001) for improvements to be made.

Finally, as Liao (2007, p.197) argues, The Map (Williams $\&$ Chesterman, 20002) and the classification of TS research areas presented in it "only allows its readers to stay at the level of distinguishing qualitative and quantitative research" (as cited in Lan et al., 2009). This could possibly convey the intention that the The Map (Williams \& Chesterman, 2002) does not provide explanation on how to choose research topics and apply the methods listed.

\section{Conclusions and Implications}

The present study aimed at investigating the tendencies of TS within different countries of the world. The work carried out with special reference to two continents of Asia and Europe. As the scope of this research was related to two continents, it presented the audience with a more extended list of results and findings. As mentioned in chapter one, broadening the aims and scopes of a research program could possibly help the researchers in presenting more generalizable data' (Cohen et al., 2007). Secondly, throughout the research, the tendencies of Iranian researchers could be compared with those of other countries including Asian on the one hand, and European on the other. This could help Iranian researchers, professors, students, etc., in their decision makings while trying to select a topic in TS. Thirdly, the most and the least worked areas in TS were investigated in different countries under study, which was carried out through a recent model presented by Williams and Chesterman (2002).

The list of findings of the study is presented as follwings:

- As the findings of the study revealed, within the twelve research areas in Translation Studies (Williams \& Chesterman, 2002), only four of the research areas held statistically significant differences, comparing Asian with European journals $(p<0.05)$. These areas included:

1) Genre Translation

2) Terminology and Glossaries

3) Translator Training

4) The Translation Profession

- The frequencies of the articles conducted in 'Multimedia Translation' research area were observed to be similar for both Asian and European journals ( $\mathrm{f}=1$ for both continents).

- Based on the results of the study, out of the twelve research areas presented by Williams and Chesterman (2002), seven of them were observed not to hold any statistically significant differences $(p>0.05)$. These included
1) Text Analysis and Translation
2) Translation Quality Assessment
3) Translation and Technology
4) Translation History
5) Translation Ethics
6) Interpreting
7) The Translation Process

- Concerning Asian journals, the most frequent research areas were observed to be 'Translator Training', 'Interpreting', and 'The Translation Process' with the observed frequencies of 16, 10, and 9 respectively.

- Concerning Asian journals, the least frequent research areas were observed to be 'The translation Profession', 'Multimedia translation', and 'terminologies and Glossaries' with the observed frequencies of 0,1 , and 1 respectively.

- Concerning European journals, the most frequent research areas were observed to be 'Genre Translation' with the frequency of 12. Likewise, 'Text Analysis and Translation', Translation History', and 'The Translation Process' shared the frequencies of 8 (i.e., the second most frequent research area in European journals).

- Concerning European journals, the least frequent research areas were observed to be 'Terminology and Glossaries', 'Translation Quality Assessment', and 'Multimedia Translation' with the observed frequencies of 0,1 , and 1 respectively.

- 'Multimedia Translation' and 'Terminology and Glossaries' were among the least frequent research areas, both in Asian and European journals. 


\section{Appendix 1. Research Area Codes Based on Williams and Chesterman (2002) Model}

1) Text Analysis and Translation

2) Translation Quality Assessment

3) Genre Translation

4) Multimedia Translation

5) Translation and Technology

6) Translation History

7) Translation Ethics

8) Terminology and Glossaries

9) Interpreting

10) The Translation Process

11) Translator Training

12) The Translation Profession

\begin{tabular}{|c|c|}
\hline Title of the Article & $\begin{array}{c}\text { Research } \\
\text { Area Code }\end{array}$ \\
\hline \multicolumn{2}{|l|}{ Translation Studies (ISSN: 1735-0212) } \\
\hline Challenges of Machine Translation in Persian, Using Three MT Systems & 5 \\
\hline Translation Criticism: A CDA Approach & 2 \\
\hline The Assessment of Difficulties of Persian Translators in Comprehension and Translation of English Compound Words & 2 \\
\hline On the Test Methods and Translation Criteria Used to Assess Iranian Students' Translation in Translation Courses & 11 \\
\hline The Relationship Between Imagination and Translation Ability of Iranian Translation Students & 10 \\
\hline Identity in Translation & 7 \\
\hline A Framework for Translation Evaluation & 2 \\
\hline Test Forms and Trainees Translation Performance & 11 \\
\hline Subtitling Norms: A Comparative Study of Iranian and American Films & 4 \\
\hline A Comparative Evaluation of Two Persian MT Systems & 5 \\
\hline Speech Acts in Drama Translation & 3 \\
\hline Cross-Cultural Problems of Translation of Compliments & 6 \\
\hline Translating the Holy Quran: Conversational Implicature & 10 \\
\hline Persian Verb-Last Sentences in Simultaneous Interpreting & 9 \\
\hline Accuracy, Clarity and Naturalness in Translation of Religious Texts & 10 \\
\hline A Comparative Study of Culture-Bound Terms in Translation: Sa'di's Gulistan or Rose Garden in Persian and English & 1 \\
\hline A Glance at the Ailing System of Teaching Translation in Some Iranian Universities & 11 \\
\hline Translation of Fiction: A Sociosemiotic Approach & 3 \\
\hline Investigating Cohesion in Simultaneous Interpretation: A Parallel corpora-Based Study & 9 \\
\hline Translation Workshops: A Study of What is Needed & 11 \\
\hline \multicolumn{2}{|l|}{ Chinese Translators Journal (ISSN: 0898-5111) } \\
\hline Court Interpreter as Institutional Gate-keeper & 9 \\
\hline Redefining the Goal of Translator Education: A Shift from Translation Competence to Literacy Development & 11 \\
\hline Cultural Translation and Globalization & 5 \\
\hline Cognitive Researches on Interpretation in the West: An Overview & 9 \\
\hline $\begin{array}{l}\text { From Translating through Translations to Translating from the Original: China's Approach to Rendering Literary Works } \\
\text { in“Minor”Languages (1949 1999) }\end{array}$ & 10 \\
\hline On the Why and the How of Re-reading Traditional Chinese Discourse on Translation Martha & 6 \\
\hline Semantic Discreteness and Integration in Translation & 10 \\
\hline A Review of Book-length Studies of Translation Published in China over the Past 60 Years & 6 \\
\hline $\begin{array}{c}\text { A Textual and Strategic Analysis of Slogan Translation: With the C-E Rendering of Shanghai World Expo Slogans as an } \\
\text { Exemplar }\end{array}$ & 1 \\
\hline Cultural Factors in Legal Translation & 3 \\
\hline
\end{tabular}




\begin{tabular}{|c|c|}
\hline $\begin{array}{l}\text { Word Choice Differences in Two English Versions of Sun-tzu's The Art of War and in Translations of Ancient Chinese } \\
\text { Classics in General: An Empirical Study }\end{array}$ & 8 \\
\hline Professional Training \& Certification of Competent Translators and the Development of Localized Translation Industry & 11 \\
\hline A Guide for Conducting Translation Workshop & 11 \\
\hline The Rhetoric of Venuti Conception of Foreignizing Translation & 6 \\
\hline Five Fundamental Concepts in Confucius's Educational Philosophy: Their Reinterpretations and English Retranslations & 11 \\
\hline Descriptive Translation Studies and Beyond & 10 \\
\hline An Allegorical Re-interpretation of Benjamin's Conception of Translation & 6 \\
\hline The Translator's Aphasia and the Missing Link in Translation Teaching & 11 \\
\hline Back to the Real World: Reflections on the "Cultural Turn" in Translation Studies & 7 \\
\hline Calling out for a New Culture of Translation: Lawrence Venuti's Scholarly Endeavors since 2009 & 6 \\
\hline \multicolumn{2}{|l|}{ Compilation and Translation Review (ISSN: 2071-4858) } \\
\hline Wuthering Heights in Taiwan: Translations, Adaptations and other Derivative Works & 10 \\
\hline Taiwanese Language Textbooks Used During the Early Period of Japanese Rule: An Historical Analysis & 11 \\
\hline Current Practices of Court Interpreting in Taiwan: Challenges and Possible Solutions & 9 \\
\hline Computer-aided Business Translation Teaching: The Use of MT and TM as Aids & 5 \\
\hline Interpreters' Views on the Necessary Aptitudes of Interpreters & 9 \\
\hline Imagining the West: Zhou Shoujuan's Pseudotranslations & 7 \\
\hline The Relationship between College Students' Translation Learning Styles and Translation Competence & 11 \\
\hline Related Issues in Taiwan's Translation Development & 5 \\
\hline Community Interpreting: A New Area of Interpreting Studies in Taiwan & 9 \\
\hline The Strategies and Style of Translating Poetry in Three Chinese Translations of The Pilgrim's Progress & 1 \\
\hline The Relationship between Translation Theory and Practice & 10 \\
\hline Literature, Translation, and the Critics: On Prémare's Translation of Le Petit Orphelin de la Maison de Tchao & 2 \\
\hline Translations of Culture-specific Menu Entries: From "Optimal Relevance" to "Meta-Representation" & 10 \\
\hline The Implications and Implementation of Communicative Translation Teaching & 11 \\
\hline The Professionalization of Interpreting in Taiwan: A Critical Review of Tseng's Model & 9 \\
\hline Translation Studies Courses in British Universities: An Overview & 11 \\
\hline Integration of Micro and Macro Approaches to Translation Teaching & 11 \\
\hline Teaching College Level Interpretation in Taiwan & 11 \\
\hline Do Interpreters Need to Sound Like Broadcasters? & 9 \\
\hline Interpretation and Evaluation & 9 \\
\hline \multicolumn{2}{|l|}{ The Translator (ISSN: 1757-0409) } \\
\hline An Epistemology of Tension: Translation and Multiculturalism & 7 \\
\hline Dynamic Equivalence Reconsidered & 6 \\
\hline Advertising: Some Challenges to Translation Theory & 3 \\
\hline Translating Advertisements across Heterogeneous Cultures & 6 \\
\hline Translating Advertising: Painting the Tip of an Iceberg & 3 \\
\hline Hiding Difference: On the Localization of Websites & 5 \\
\hline From Culture to Business: Federal Government Translation in Canada & 6 \\
\hline $\begin{array}{l}\text { Between Literacy and Non-Literacy: Interpreters in the Exploration and Colonization of Eighteenth and Nineteenth-Century } \\
\text { Alaska }\end{array}$ & 9 \\
\hline Scribes of a Transnational Europe: Travel, Translation, Borders & 3 \\
\hline Decolonizing Translation: Language, Culture and Self & 6 \\
\hline Reflexivity and the Social Construction of Identity in Interpreter-mediated Asylum Interviews & 7 \\
\hline Translator Status: A Study of Danish Company Translators & 3 \\
\hline Style Differences among Simultaneous Interpreters: A Pilot Study & 9 \\
\hline Ethical Problems in Translation: Why We Might Need Steiner After All & 7 \\
\hline Data Documentation and Data Accessibility in Translation Process Research & 10 \\
\hline
\end{tabular}




\begin{tabular}{|c|c|}
\hline Inimitability versus Translatability. The Structure of Literary Meaning in Arabo-Persian Poetics & 1 \\
\hline Translator Style: Methodological Considerations & 3 \\
\hline A Window into the Profession: What Translation Blogs Have to Offer Translation Studies & 12 \\
\hline A Testament to Translation Criticism: Antoine Berman's Final Work & 2 \\
\hline Postcolonial Polysystems: Perceptions of Norms in the Translation of Children's Literature in South Africa & 3 \\
\hline \multicolumn{2}{|l|}{ Target (ISSN: 1569-9986) } \\
\hline Propositions on cross-cultural communication and translation & 3 \\
\hline Intercultural relations between Arabs and Israeli Jews as reflected in Arabic translations of modern Hebrew literature & 3 \\
\hline Dialogue interpreting: A monologising practice in a dialogically organised world & 9 \\
\hline How to be a (recognized) translator: Rethinking habitus, norms, and the field of translation & 7 \\
\hline Methodological questions about translation research: A model to underpin research into the mental processes of translation & 10 \\
\hline Translation curriculum and pedagogy: Views of administrators of translation services & 11 \\
\hline Translation in global news agencies & 12 \\
\hline Translation technologies: Scope, tools and resources & 5 \\
\hline A missing link in Itamar Even-Zohar's theoretical thinking & 6 \\
\hline Is Translation Studies too much about translation?: A reply to Jan Blommaert & 6 \\
\hline Interpreting accent in the courtroom & 9 \\
\hline Censorship and translated children's literature in the Soviet Union: The example of the Wizards Oz and Goodwin & 3 \\
\hline The death of the translator in machine translation: A bilingual poetry project & 5 \\
\hline Explicitations and other types of shifts in the translation of irony and humor & 10 \\
\hline Flow in translation: Exploring optimal experience for translation trainees & 11 \\
\hline In defence of polysystem theory & 6 \\
\hline Cultural mediation through translingual narrative & 3 \\
\hline Agency in the translation and production of The Adventures of Hajji Baba of Ispahan into Persian & 1 \\
\hline The effect of translator training on interference and difficulty & 11 \\
\hline Revision from translators' point of view: An interview study & 3 \\
\hline \multicolumn{2}{|l|}{ Across Language and Cultures (ISSN: 1585-1923) } \\
\hline Keywords and Ideology in Translated History Texts: A Corpus-Based Analysis & 6 \\
\hline Point of View in Translation: a Corpus-Based Study of French Translations of Virginia Woolf's To The Lighthouse & 1 \\
\hline Case Studies In Translation: The Study Of Translation Cases & 10 \\
\hline From Translation to Transfer & 10 \\
\hline Translating New Genres Between Slovene and English: An Analytical Framework & 3 \\
\hline Colloquialisms in translated text. Double illusion? & 10 \\
\hline The Authoritativeness of Translations & 3 \\
\hline Archaisation, Modernisation and Reference in the Translation of Older Texts & 1 \\
\hline Dylan Dog Goes to the USA: A North-American Translation of an Italian Comic Book Series & 1 \\
\hline Addressing power and solidarity in TV subtitling & 4 \\
\hline The Translation of English Dialectal Dramatic Dialogue into Arabic & 10 \\
\hline 'Two Thirds Of A Boy Are His Uncle's': The Question Of Relevance In Translation & 1 \\
\hline Translating Bilinguality: Theorizing Translation in the Post-Babelian Era & 10 \\
\hline Second Language Acquisition: Language Teaching and Translation Studies & 11 \\
\hline A Cognitive Approach to Literary Humour Devices: Translating Raymond Chandler & 1 \\
\hline Humour in Simultaneous Conference Interpreting & 9 \\
\hline Possess Yourselves of the Soil: Interpreting in Early New Zealand & 9 \\
\hline Between a Grand Tradition and the Profession & 12 \\
\hline Ethos, Ethics and Translation: Toward a Community of Destinies & 7 \\
\hline Introduction: The Return to Ethics in Translation Studies & 7 \\
\hline
\end{tabular}




\section{REFERENCES}

[1] Bowker, L., Cronin, M., Kenny, D., \& Pearson, J. (1998). Unity in diversity? Current trends in translation studies. Manchester: St. Jerome.

[2] Catford, J. C. (1965). A linguistic theory of translation. London: Oxford University Press.

[3] Chambers Concise Dictionary. (1989). Edited by Davidson, George W., M.A. Scaton and J. Simpson. Chambers: Cambridge.

[4] Cohen, L., Manion, L., \& Morrison, K. (2007). Research methods in education. (6th ed.). Washington, DC: Taylor \& Francis.

[5] Gillham, B. (2000). Case study research methods. London \& New York: Continuum.

[6] Hatim, B. (2001). Translating and researching translation. London \& New York: Longman.

[7] Holmes, J. S. (1988). The name and nature of translation studies, In L. Venuti (Ed.) The Translation Studies Reader. (pp.172-185). New York: Routledge.

[8] Kurz, I. (2001). Small projects in interpretation research. In D. Gile, H.V. Dam, F. Dubslaff, B. Martinsen \& A. Schjoldager (Eds.), Getting started in interpreting research: Methodological reflections, personal accounts and advice for beginners. (pp. 101-120). Amsterdam \& Philadelphia: John Benjamins.

[9] Lan, Y., Dong, D., \& Chiu, A. (2009). Research trend and methods in Translation Studies: A comparison between Taiwanese and international publications. Compilation and Translation Review, 2(2), pp.177-191.

[10] Liao, P. (2007). The review of current interpretation research publications in Taiwan. Studies of translation and interpretation, (10), pp.189-217.

[11] Munday, J. (2008). Introducing translation studies: Theories and applications (2nd ed.). London: Routledge.

[12] Newmark, P. (1988). A textbook of translation. New York: Prentice Hall International.

[13] Snell-Hornby, M. (1995). Translation studies: An integrated approach (Rev. ed.). Amsterdam: John Benjamins.

[14] Toury, G. (1995). Descriptive translation studies and beyond. Amsterdam: John Benjamins.

[15] Vinay, J. P., \& Darbelnet, J. (1958) Stylistique comparée du français et de l'anglais: Méthode de traduction, Paris: Didier, translated and edited by J. C. Sager and M. J. Hamel (1995) as Comparative Stylistics of French and English: A Methodology for Translation, Amsterdam and Philadelphia, PA: John Benjamins.

[16] Williams, J., \& Chesterman, A. (2002). The map: A beginner's guide to doing research in translation studies. Manchester, U.K.: St. Jerome Pub.

[17] Yuan, L., \& Tang, J. (2007). The 2001-2006 domestic translation studies measurement analysis - based on three kinds of translation. Shanghai Translation, 3, pp. 19-22. 